\title{
Organic Fertilization and Its Effect on Development of Sweet Pepper Transplants
}

\author{
Valérie Gravel ${ }^{1}$, Martine Dorais, and Claudine Ménard \\ Agriculture and Agri-Food Canada, Centre de recherche en horticulture, \\ Pavillon Envirotron, Université Laval, Québec, QC G1V 0A6, Canada
}

Additional index words. Capsicum annuum, organic farming, shrimp meal, kelp meal, Trichoderma harzianum

\begin{abstract}
Organically grown greenhouse sweet pepper crops, as is the case with most year-around greenhouse crops, rely on pre-grown transplants. Production of adequately balanced (source and sink strength potential) healthy organic sweet pepper transplants is a challenge and is often related to early and total harvested yields. Liquid and/or solid organic fertilizers for greenhouse sweet pepper transplants were compared with a conventional liquid fertilizer. Transplants were grown under greenhouse conditions and inoculated, or not, with a beneficial microbial agent, Trichoderma harzianum Rifai, strain KRL-AG2 (Rootshield $\left.{ }^{\circledR}\right)$. Medium respiration $\left(\mathrm{CO}_{2}\right.$ efflux) and fluorescein diacetate (FDA) hydrolysis analysis showed a higher microbial activity in the liquid organic fertilizer treatment. Higher microbial activity was observed after 10 weeks than at 5 weeks after transplanting. Transplant development was greater in the liquid conventional fertilizer treatment compared with the two organic treatments. Transplants that received liquid organic fertilizer had greater development compared with transplants that only received water in addition to the initial solid fertilizer. Organic amendment mineralization did not completely fulfill transplant nutrient requirement compared with conventional transplants. Solid fertilization in the growing medium affected plant growth during the first 5 weeks but not after 10 weeks after transplanting. Solid and liquid organic fertilizers at a higher concentration should be provided to reach a similar transplant development because conventional seedlings or other slow-release sources of solid amendments should be added to the growing medium to keep an adequate and constant nutrient release. Providing a beneficial agent to the organic growing medium increased its biological activity but had no effect on seedling growth during this study. Solid organic fertilization $\left(1600 \mathrm{~mL} \cdot \mathrm{m}^{-3}\right.$ of shrimp meal with $50 \mathrm{~mL} \cdot \mathrm{m}^{-3}$ of kelp meal) combined with an organic liquid fertilization should be used in combination with inoculation with $T$. harzianum to obtain high-quality organic sweet pepper transplants.
\end{abstract}

Consumers and growers have become more conscious of how consumed goods are produced and if foods present any risk for human health in terms of pesticide residues. In contrast to conventional production systems in which plant nutrition is based on using synthetic and well-balanced fertilizers in excess of plant uptake, organic horticulture is based on an integrated agrosystem using organic fertilizer input (Dorais, 2007). Because greenhouse vegetables are produced under an intensive growing system as a result of high investment, high-quality transplants are required. Greenhouse transplants should have a good developmental balance between shoot and roots, high water use efficiency, and a high content of reserves that can be used in the first stages of crop establishment in the

\footnotetext{
Received for publication 1 Sept. 2011. Accepted for publication 19 Dec. 2011.

This research was funded through Canada's Organic Science Cluster, which in turn is funded by the Canadian Agri-Science Clusters Initiative of Agriculture and Agri-Food Canada's Growing Forward Policy Framework and its industry partners. ${ }^{1}$ To whom reprint requests should be addressed; e-mail valerie.gravel@agr.gc.ca.
}

greenhouse (Tremblay and Gosselin, 1998; Tremblay and Sénécal, 1988). Well-rooted seedlings that will ensure appropriate nutrient uptake under limited nutrient supply as well as potential leaf area and a balanced relationship between source and sink strength are important properties of sweet pepper (Capsicum annuum L.) that have a strong impact on light interception, photosynthesis, and then fruit abortion (Wubs et al., 2011). Consequently, producing high-quality and pathogen-free organic transplants has become a challenge to ensure grower profitability. Production of organic vegetable transplants has been done using both solid and liquid sources of organic fertilizers (Koller et al., 2004). Organic amendments such as compost and manure have also been shown to be a good source of fertilization in container-grown organic plant production (Raviv et al., 2005). Plant- and animal-based fertilizers have previously been tested in the production of vegetable transplants with various results (Gagnon and Berrouard, 1994; Koller et al., 2004; Raviv et al., 1998; Russo, 2005; Schnurer and Rosswall, 1982). Organic crop fertilization is often based on mineralization of nutrient sources, which is not always convenient for production of potted or container- grown plants such as vegetable transplants. This is caused, in part, by a slow mineralization rate of nutrients; the presence in high concentrations of unwanted ions such as $\mathrm{SO}_{4}$, sodium, or chlorine, which can result in salinization of the organic growing medium (Gravel et al., 2011); and an inadequate $\mathrm{NH}_{4}: \mathrm{NO}_{3}$ ratio for optimal plant growth (Dorais, 2007). Solid organic fertilizers are often unbalanced in their nutrient content, especially in mutual nitrogen, phosphorus, and potassium ratios, and a delay in shoot growth can result from their use (Jack et al., 2011; Voogt et al., 2011). Although bell pepper transplant needs for nutrients is relatively small compared with a mature crop, an adequate level of nutrients is necessary to ensure optimal development and well-balanced plants during the first 8 weeks. In addition, use of beneficial microorganisms increases efficiency of organic fertilizers (Perner et al., 2007). Such beneficial microorganisms, which can be naturally present in organic fertilizers and growing medium, not only affect early growth of transplants, but can also result in improved growth later on in organic greenhouse vegetable production.

To achieve high-quality organic transplants for greenhouse sweet pepper production, the objectives of this study were to: 1) compare an organic growing system based on liquid and/or solid fertilizers for sweet pepper transplants with a conventional system for plant growth; 2) evaluate, especially for an organic growing system, use of beneficial agents such as Trichoderma harzianum (Rootshield ${ }^{\circledR}$ ) on sweet pepper growth; and 3) assess effects of fertilization on the microbial activity within the growing medium.

\section{Materials and Methods}

Plant material. Seeds of sweet pepper, cv. Aristotle X3R, were sown in multicellular trays ( 200 cells; $14 \mathrm{~mL}$ per cell) containing an organic peat-based growing medium (Berger OM1; Les Tourbières Berger Ltée, St-Modeste, Quebec, Canada). Twenty d later, seedlings were transplanted to $15-\mathrm{cm}$ plastic pots containing the same OM1 growing medium. Growing conditions remained constant during the course of the experiment $(90 \mathrm{~d})$ : temperatures of $22{ }^{\circ} \mathrm{C}$ (day) and $17{ }^{\circ} \mathrm{C}$ (night), $70 \%$ relative humidity, natural daylight supplemented with high-pressure sodium lamps $\left(100 \mu \mathrm{mol} \cdot \mathrm{m}^{-2} \cdot \mathrm{s}^{-1}\right)$ for a $12-\mathrm{h}$ photoperiod. $\mathrm{No} \mathrm{CO}_{2}$ enrichment was provided.

Solid organic fertilization. The organic growing medium was enriched, or not, with 16 solid organic fertilizers before transplanting (Table 1). Organic fertilizers were chosen for their wide availability, their common use by growers, and their N-P-K content. Shrimp meal $8.5 \mathrm{~N}-2.6 \mathrm{P}-1 \mathrm{~K}$ (Distrival Canada Ltée, Fortierville, Quebec, Canada) was incorporated at a rate of $0,400,800$ or $1600 \mathrm{~mL} \cdot \mathrm{m}^{-3}$ in the growing medium (Table 1). Kelp meal $0.5 \mathrm{~N}-0.08 \mathrm{P}-14.4 \mathrm{~K}$ (Distrival Canada Ltée) was also incorporated at a rate of 0 or $50 \mathrm{~mL} \cdot \mathrm{m}^{-3}$ in the growing medium (Table 1). The nitrogen $(\mathrm{N})$, phosphorus $(\mathrm{P})$, potassium $(\mathrm{K})$, and calcium contents in the growing mixes before 
Table 1. Solid fertilization, mineral content, and T. harzianum inoculation in the growing medium used for production of sweet pepper transplants.

\begin{tabular}{|c|c|c|c|c|c|c|c|}
\hline \multirow{2}{*}{$\begin{array}{l}\text { Growing } \\
\text { medium mixes }\end{array}$} & \multirow{2}{*}{$\begin{array}{l}\text { Shrimp meal } \\
\left(\mathrm{mL} \cdot \mathrm{m}^{-3}\right)\end{array}$} & \multirow{2}{*}{$\begin{array}{l}\text { Kelp meal }{ }^{y} \\
\left(\mathrm{~mL} \cdot \mathrm{m}^{-3}\right)\end{array}$} & \multirow{2}{*}{$\begin{array}{l}\text { T. } \text { harzianum }^{\mathrm{x}} \\
\left(\mathrm{mL} \cdot \mathrm{m}^{-3}\right)\end{array}$} & \multicolumn{4}{|c|}{ Mineral content } \\
\hline & & & & Nitrogen $\left(\mathrm{g} \cdot \mathrm{m}^{-3}\right)$ & Phosphorus $\left(\mathrm{g} \cdot \mathrm{m}^{-3}\right)$ & Potassium $\left(\mathrm{g} \cdot \mathrm{m}^{-3}\right)$ & Calcium $\left(\mathrm{g} \cdot \mathrm{m}^{-3}\right)$ \\
\hline $0 \mathrm{~mL} \mathrm{SM}{ }^{\mathrm{w}} ; 0 \mathrm{~mL} \mathrm{KM}{ }^{\mathrm{v}} ; \mathrm{C}^{\mathrm{u}}$ & 0 & 0 & 0 & 0 & 0 & 0 & 0 \\
\hline $0 \mathrm{~mL} \mathrm{SM} ; 0 \mathrm{~mL} \mathrm{KM} ; \mathrm{T}^{\mathrm{t}}$ & 0 & 0 & 100 & 0 & 0 & 0 & 0 \\
\hline $0 \mathrm{~mL} \mathrm{SM} ; 50 \mathrm{~mL} \mathrm{KM}$; C & 0 & 50 & 0 & 0.5 & 0.8 & 14.4 & 0.3 \\
\hline 0 mL SM; 50 mL KM; T & 0 & 50 & 100 & 0.5 & 0.8 & 14.4 & 0.3 \\
\hline 400 mL SM; 0 mL KM; C & 400 & 0 & 0 & 68.0 & 20.8 & 8.0 & 58.4 \\
\hline 400 mL SM; 0 mL KM; T & 400 & 0 & 100 & 68.0 & 20.8 & 8.0 & 58.4 \\
\hline 400 mL SM; 50 mL KM; C & 400 & 50 & 0 & 68.5 & 21.6 & 22.4 & 58.7 \\
\hline 400 mL SM; 50 mL KM; T & 400 & 50 & 100 & 68.5 & 21.6 & 22.4 & 58.7 \\
\hline 800 mL SM; 0 mL KM; C & 800 & 0 & 0 & 136.0 & 41.6 & 16.0 & 116.8 \\
\hline 800 mL SM; 0 mL KM; T & 800 & 0 & 100 & 136.0 & 41.6 & 16.0 & 116.8 \\
\hline 800 mL SM; 50 mL KM; C & 800 & 50 & 0 & 136.5 & 42.4 & 30.4 & 117.1 \\
\hline 800 mL SM; 50 mL KM; T & 800 & 50 & 100 & 136.5 & 42.4 & 30.4 & 117.1 \\
\hline $1600 \mathrm{~mL} \mathrm{SM} ; 0$ mL KM; C & 1600 & 0 & 0 & 272.0 & 83.2 & 32.0 & 233.6 \\
\hline 1600 mL SM; 0 mL KM; T & 1600 & 0 & 100 & 272.0 & 83.2 & 32.0 & 233.6 \\
\hline $1600 \mathrm{~mL} \mathrm{SM} ; 50 \mathrm{~mL} \mathrm{KM}$; C & 1600 & 50 & 0 & 272.5 & 84.0 & 46.4 & 233.9 \\
\hline $1600 \mathrm{~mL} \mathrm{SM} ; 50 \mathrm{~mL} \mathrm{KM}$; T & 1600 & 50 & 100 & 272.5 & 84.0 & 46.4 & 233.9 \\
\hline
\end{tabular}

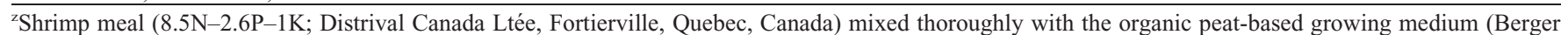
OM1; Les Tourbières Berger Ltée, St-Modeste, Quebec, Canada) before transplanting.

y Kelp meal (0.5N-0.08P-14.4K; Distrival Canada Ltée) mixed thoroughly with the organic peat-based growing medium before transplanting.

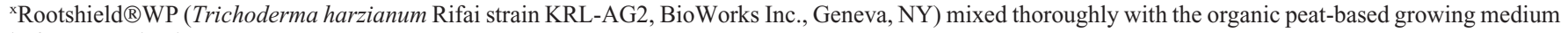
before transplanting.

${ }^{\mathrm{w}} \mathrm{SM}=$ shrimp meal.

${ }^{\mathrm{v}} \mathrm{KM}=$ kelp meal.

${ }^{\mathrm{u}} \mathrm{C}=$ control.

${ }^{\mathrm{t}} \mathrm{T}=$ Trichoderma harzianum.

transplanting differed (Table 1). The beneficial microbial inoculant $T$. harzianum Rifai, strain KRL-AG2 (Rootshield ${ }^{\circledR} W P$; BioWorks Inc., Geneva, NY; $100 \mathrm{~mL} \cdot \mathrm{m}^{-3}$ ), was added to the growing medium before transplanting. For control, the growing medium was not inoculated with $T$. harzianum.

Liquid fertilization. After transplanting, sweet pepper plants received water, conventional synthetic fertilization, or organic fertilization. Plants were fertilized three times a week (Monday, Wednesday, and Friday) with their respective nutrient solutions and plants were watered daily as needed. Conventional fertilization consisted of a nutrient solution with an electrical conductivity (EC) of 1.5 $\mathrm{mS} \cdot \mathrm{cm}^{-1}$ and made with the soluble fertilizers 6N-4.8P-25.7K (Plant-Prod, Laval, Quebec, Canada) and calcium nitrate $15.5 \mathrm{~N}-0 \mathrm{P}-0 \mathrm{~K}$ (Plant-Prod). Organic liquid fertilization was with a nutrient solution consisting of a $0.2 \%$ dilution of Daniels ${ }^{\circledR}$ Pinnacle $3 \mathrm{~N}-0.4 \mathrm{P}-0.8 \mathrm{~K}$ (Daniels ${ }^{\circledR}$ Plant Food, Sherman, TX) using an injection irrigation system.

The experimental design was a split-splitplot design with five replicates. Main plots (three liquid fertilization treatments), subplots (eight solid fertilization treatments), and subsubplots (biological inoculant treatments) were randomized within each block. Each experimental unit consisted of two sweet pepper plants (one plant for each of biomass evaluation) for a total of 10 plants per treatment.

Evaluation of plant growth and development. Plant growth was evaluated at 5 and 10 weeks after transplanting on one plant per experimental unit. Numbers of leaves per plant were counted. Fresh and dry weights of the shoot were measured. Roots were washed thoroughly with tap water to remove all growing medium after which fresh and dry weights were measured ( 5 weeks evaluation only). Carbohydrate partitioning, either on a fresh or dry basis, was calculated using the following formulas: $\%$ of partitioning in shoot $=$ (weight of shoot/total weight of plant) $\times 100$ and $\%$ of partitioning in roots $=$ (weight of roots/total weight of plant) $\times 100$.

$\mathrm{CO}_{2}$ emission from the growing medium. $\mathrm{CO}_{2}$ efflux emitting from the growing medium, as an indicator of soil biological activity, was evaluated 5 weeks after transplanting using $\mathrm{a} \mathrm{CO}_{2}$ flux chamber (Li-6400-09; LI-COR Inc., Lincoln, NE) placed directly on the surface of the pots (total volume of $1.5 \mathrm{~L}$ ). Results for media respiration were expressed in $\mu \mathrm{mol}$ $\mathrm{CO}_{2} / \mathrm{cm}^{2} / \mathrm{s}$.

Determination of fluorescein diacetate hydrolysis. An estimation of the growing medium general microbial activity was performed 5 and 10 weeks after transplanting using a modified version of the method described by Schnurer and Rosswall (1982). Briefly, a 2-g sample of the growing medium was mixed with $20 \mathrm{~mL}$ of sterile distilled water. Then, $60 \mu \mathrm{L}$ of a stock solution of FDA $\left(2 \mathrm{mg} \cdot \mathrm{L}^{-1}\right)$ was added before incubation at $28^{\circ} \mathrm{C}$ for $1 \mathrm{~h}$. Samples were centrifuged at $3075 \mathrm{~g}$ for $5 \mathrm{~min}$ and hydrolysis of FDA was measured by absorbance at $490 \mathrm{~nm}$ using a spectrophotometer (Hitachi U-1100, Toronto, Ontario, Canada).

pH and electrical conductivity of growing medium. Water $\mathrm{pH}$ of each of the mixes of growing medium and solid fertilization was measured before transplanting. Briefly, $15 \mathrm{~cm}^{3}$ of soil was mixed with $15 \mathrm{~mL}$ of distilled water and stirred every $5 \mathrm{~min}$ for $30 \mathrm{~min}$, after which $\mathrm{pH}$ was measured (Accumet ${ }^{\circledR}$ Excel XL50; Fisher Scientific, Ottawa, Ontario, Canada). Soil EC was measured using $10 \mathrm{~cm}^{3}$ of soil mixed thoroughly with $20 \mathrm{~mL}$ of distilled water. Once solids had settled, EC was measured (Accumet ${ }^{\circledR}$ Excel XL50). pH and EC were also measured at the end of the experiment ( $70 \mathrm{~d}$ of growth) using the same methods.
Statistical analyses. Effects of liquid fertilization, solid fertilization (shrimp meal and kelp meal), and beneficial microbial inoculation and the interaction of these effects on plant growth, $\mathrm{CO}_{2}$ effluxes, microbial activity, $\mathrm{pH}$, and EC were analyzed using orthogonal contrasts (SAS Institute, Cary, NC) with a level of significance of $P \leq 0.05$. In total, 50 contrasts were evaluated. Simple effects of liquid fertilization, solid fertilization, and beneficial microbial inoculation were also analyzed using the SAS Mixed Models procedure (SAS Institute, Cary, NC) with replicates as the random effect.

\section{Results}

Evaluation of plant growth and development. Significant contrasts for plant biomass $(P<$ 0.05 ) are presented in Table 2. Five weeks after transplanting, a visual evaluation of sweet pepper transplants in general did not exhibit marked differences between organic and conventional treatments but significant effects were measured for growth parameters (Table 3 ). Control plants receiving water only were smaller and were a lighter shade of green, observations that are reflected in the fresh weight of plants (Table 3 ). This was especially noticeable 10 weeks after transplanting. After 5 and 10 weeks after transplanting into the growing medium, the interaction among liquid fertilization, solid fertilization (shrimp and kelp meal), and inoculation with the beneficial inoculant was not statistically different for fresh shoot weight, dry shoot weight, and stem length. Inoculation with beneficial inoculant and kelp meal did not have a significant effect on plant growth at Week 5 and Week 10 for all evaluated parameters (data not shown).

A significant effect resulting from liquid fertilization was observed on plant growth at both biomass evaluation (Table 3 ). After 


\begin{tabular}{|c|c|c|c|c|c|c|c|c|c|c|c|c|}
\hline \multirow[b]{4}{*}{ Contrasts $^{z}$} & & & \multirow{4}{*}{$\begin{array}{l}\text { Shoot length } \\
\quad(5 \mathrm{~W})\end{array}$} & & & \multirow{4}{*}{$\begin{array}{l}\text { Shoot length } \\
(10 \mathrm{~W})\end{array}$} & & & \multicolumn{4}{|c|}{ Carbohydrate partitioning } \\
\hline & \multirow{2}{*}{\multicolumn{2}{|c|}{ Shoot wt $\left(5 \mathrm{~W}^{\mathrm{y}}\right)$}} & & & & & & & \multicolumn{2}{|c|}{ (fresh wt) } & \multicolumn{2}{|c|}{ (dry wt) } \\
\hline & & & & \multicolumn{2}{|c|}{ Shoot wt $(10 \mathrm{~W})$} & & \multicolumn{2}{|c|}{ Root wt (5 W) } & \multirow{2}{*}{$\begin{array}{c}\text { Percent } \\
\text { shoot }\end{array}$} & \multirow{2}{*}{$\begin{array}{c}\text { Percent } \\
\text { root }\end{array}$} & \multirow{2}{*}{$\begin{array}{c}\text { Percent } \\
\text { shoot }\end{array}$} & \multirow{2}{*}{$\begin{array}{c}\text { Percent } \\
\text { root }\end{array}$} \\
\hline & Fresh & Dry & & Fresh & Dry & & Fresh & Dry & & & & \\
\hline $\mathrm{O}^{\mathrm{w}}$ vs. $\mathrm{C}^{\mathrm{v}}$ & 0.0115 & 0.0072 & $<0.0001$ & $<0.0001$ & $<0.0001$ & $<0.0001$ & 0.0433 & 0.0443 & NS & NS & NS & NS \\
\hline $\mathrm{O}$ vs. $\mathrm{Wa}^{\mathrm{u}}$ & $<0.0001$ & $<0.0001$ & NS & $<0.0001$ & $<0.0001$ & $<0.0001$ & 0.0004 & 0.0070 & $<0.0001$ & $<0.0001$ & $<0.0001$ & $<0.0001$ \\
\hline C vs. Wa & $<0.0001$ & $<0.0001$ & $<0.0001$ & $<0.0001$ & $<0.0001$ & $<0.0001$ & NS & $<0.0001$ & $<0.0001$ & $<0.0001$ & $<0.0001$ & $<0.0001$ \\
\hline $\mathrm{SM}^{\mathrm{t}}$ linear (L) & $\mathrm{NS}^{\mathrm{x}}$ & NS & $<0.0001$ & NS & NS & $<0.0001$ & NS & NS & NS & NS & NS & NS \\
\hline SM quadratic (Q) & 0.0046 & 0.0154 & NS & NS & NS & NS & NS & NS & NS & NS & NS & NS \\
\hline$(\mathrm{O}$ vs. $\mathrm{C}) * \mathrm{SM} Q$ & NS & NS & NS & NS & 0.0018 & NS & NS & NS & NS & NS & NS & NS \\
\hline$(\mathrm{O}$ vs. C)*SM C & NS & NS & NS & NS & 0.0327 & NS & NS & NS & NS & NS & NS & NS \\
\hline$(\mathrm{O}$ vs. Wa)*SM C & 0.0154 & NS & NS & NS & NS & NS & NS & NS & NS & NS & NS & NS \\
\hline$(\mathrm{C} \text { vs. Wa })^{*} \mathrm{SM} \mathrm{L}$ & 0.0187 & NS & NS & NS & NS & NS & NS & NS & NS & NS & NS & NS \\
\hline$(\mathrm{C}$ vs. Wa)*SM Q & NS & NS & NS & NS & 0.0349 & NS & NS & NS & NS & NS & NS & NS \\
\hline$(\mathrm{C} \text { vs. Wa })^{*} \mathrm{SM} \mathrm{C}$ & 0.0213 & NS & NS & NS & 0.0253 & NS & NS & NS & NS & NS & NS & NS \\
\hline $\mathrm{SM} Q * \mathrm{KM}$ & 0.0023 & NS & NS & NS & NS & NS & NS & NS & NS & NS & NS & NS \\
\hline
\end{tabular}

Data were analyzed using contrasts with a level of significance of $P \leq 0.05$.

${ }^{\mathrm{z}}$ Only contrasts with a significant $P$ value for at least one of the parameter tested are shown.

${ }^{\mathrm{y}} \mathrm{W}=$ weeks

$\mathrm{x}_{\mathrm{NS}}=$ nonsignificant.

${ }^{\mathrm{w}} \mathrm{O}=$ organic liquid fertilization.

${ }^{\mathrm{v}} \mathrm{C}=$ conventional liquid fertilization

${ }^{\mathrm{u}} \mathrm{Wa}=$ water only.

${ }^{\mathrm{t}} \mathrm{SM}=$ shrimp meal.

Table 3. Effects of liquid fertilization on shoot weight and stem length of sweet pepper transplants grown for 5 and 10 weeks under organic and conventional fertilization.

\begin{tabular}{lccc}
\hline & \multicolumn{2}{c}{ Shoot wt } & \\
\cline { 2 - 4 } & Fresh $(\mathrm{g})$ & Dry $(\mathrm{g})$ & Stem length $(\mathrm{cm})$ \\
\hline 5 weeks AT & & \\
$\quad$ Organic & 49.8 & 5.2 & 28.6 \\
$\quad$ Conventional & 51.9 & 5.5 & 30.7 \\
$\quad$ Water only & 35.7 & 4.4 & 28.5 \\
Contrasts $(P)$ & & & $<0.0001$ \\
$\quad$ Organic vs. conventional & 0.0115 & 0.0072 & NS $^{\mathrm{y}}$ \\
$\quad$ Organic vs. water & $<0.0001$ & $<0.0001$ & $<0.0001$ \\
$\quad$ Conventional vs. water & $<0.0001$ & $<0.0001$ & 58.6 \\
10 weeks AT & 346.7 & & 65.8 \\
$\quad$ Organic & 561.4 & 43.1 & 34.7 \\
$\quad$ Conventional & 63.8 & 7.5 & $<0.0001$ \\
$\quad$ Water only & & & $<0.0001$ \\
Contrasts $(P)$ & $<0.0001$ & $<0.0001$ & $<0.0001$ \\
$\quad$ Organic vs. conventional & $<0.0001$ & $<0.0001$ & \\
$\quad$ Organic vs. water & $<0.0001$ & $<0.0001$ & \\
$\quad$ Conventional vs. water & &
\end{tabular}

Data were analyzed using contrasts with a level of significance of $P \leq 0.05$.

${ }^{\mathrm{z}} \mathrm{AT}=$ after transplanting.

${ }^{\mathrm{y}} \mathrm{NS}=$ nonsignificant.

Data are means of $n=5$.

5 weeks, plant height in the conventional treatment was significantly taller than the organic $(6.8 \%)$ and water only $(7.2 \%)$ treatment plants, which had similar stem lengths (Table 3). Weight of the shoot (fresh and dry) was higher for the conventional compared with the two other treatments. Weights of the organic transplants were $95.9 \%$ and $94.5 \%$ that of conventional ones for fresh and dry weight, respectively, compared with $72.2 \%$ and $80.0 \%$ for the water-only transplants (Table 3). After 10 weeks, similar results for plant weight were observed with a significant difference between organic and water only transplants. At that time, fresh and dry weights of organic transplants were $61.8 \%$ and $87.1 \%$ that of conventional ones compared with only $11.4 \%$ and $15.2 \%$ for the water-only transplants (Table 3 ). Plants were significantly shorter for organic and water only treatments with $89.1 \%$ and
$52.7 \%$ of conventional plant height, respectively (Table 3).

Addition of shrimp meal affected plant growth during the first 5 weeks after transplanting (Table 4). At 5 weeks, the highest weight was for plants in the growing medium containing $800 \mathrm{~mL} \cdot \mathrm{m}^{-3}$ of shrimp meal, whereas the lowest were for plants receiving 0 and $1600 \mathrm{~mL} \cdot \mathrm{m}^{-3}$ of shrimp meal (Table 4). Plant height increased as amounts of shrimp meal increased (Table 4). After 10 weeks, similar results were observed for plant height (linear effect), but amounts of fertilization initially added in the growing medium did not affect final plant fresh and dry weights (Table 4). Plants were shorter in the medium containing no organic fertilizers compared with plants grown in the medium containing 1600 $\mathrm{mL} \cdot \mathrm{m}^{-3}$ of shrimp meal (Table 4$)$. Fresh and dry root weights were significantly lower for
Table 4. Effects of solid fertilization with shrimp meal on shoot weight and stem length of sweet pepper transplants after 5 and 10 weeks of growth.

\begin{tabular}{|c|c|c|c|}
\hline & \multicolumn{2}{|c|}{ Shoot wt } & \multirow{2}{*}{$\begin{array}{l}\text { Stem length } \\
(\mathrm{cm})\end{array}$} \\
\hline & $\overline{\text { Fresh }(\mathrm{g})}$ & $\overline{\text { Dry }(g)}$ & \\
\hline \multicolumn{4}{|l|}{$\overline{5 \text { weeks } \mathrm{AT}^{\mathrm{z}}}$} \\
\hline $0 \mathrm{~mL} \mathrm{SM}^{\mathrm{y}}$ & 44.9 & 4.9 & 28.2 \\
\hline $400 \mathrm{~mL} \mathrm{SM}$ & 46.3 & 5.1 & 29.0 \\
\hline $800 \mathrm{~mL} \mathrm{SM}$ & 47.4 & 5.2 & 30.1 \\
\hline $1600 \mathrm{~mL} \mathrm{SM}$ & 44.8 & 4.9 & 29.7 \\
\hline \multicolumn{4}{|l|}{ Contrasts $(P)$} \\
\hline SM linear & $\mathrm{NS}^{\mathrm{x}}$ & NS & $<0.0001$ \\
\hline SM quadratic & 0.0046 & 0.0154 & NS \\
\hline \multicolumn{4}{|l|}{10 weeks AT } \\
\hline $0 \mathrm{~mL} \mathrm{SM}$ & 321.7 & 32.8 & 51.0 \\
\hline $400 \mathrm{~mL} \mathrm{SM}$ & 323.3 & 32.4 & 52.0 \\
\hline $800 \mathrm{~mL} \mathrm{SM}$ & 327.9 & 33.6 & 53.9 \\
\hline $1600 \mathrm{~mL} \mathrm{SM}$ & 317.2 & 33.8 & 55.4 \\
\hline \multicolumn{4}{|l|}{ Contrasts $(P)$} \\
\hline SM linear & NS & NS & $<0.0001$ \\
\hline
\end{tabular}

Data were analyzed using contrasts with a level of significance of $P \leq 0.05$.

${ }^{\mathrm{z}} \mathrm{AT}=$ after transplant.

${ }^{\mathrm{y}} \mathrm{SM}=$ shrimp meal (amount mixed in $1 \mathrm{~m}^{3}$ of growing medium).

${ }^{\mathrm{x} S}=$ nonsignificant.

Data are means of $\mathrm{n}=5$. Contrast for SM cubic was not significant at $P<0.05$ for all measured parameters at 5 weeks, whereas SM quadratic and cubic were not significant at $P<0.05$ for all measured parameters at 10 weeks.

plants receiving organic liquid fertilization compared with the other treatments (Table 5). Highest root mass was for transplants receiving water only (Table 5).

On a fresh weight basis, carbohydrate partitioning between plant organs was similar for organic and conventional treated plants (Table 6). A higher proportion allocated to roots was for plants receiving only water with a ratio of $76.8 \%$ shoot to $23.2 \%$ roots (Table 6). When expressed on a dry weight basis, carbohydrate partitioning to the shoot was higher for organic and conventional plants compared with water-only plants (Table 6). 
Table 5. Effects of solid and liquid fertilizer and inoculation with a beneficial microorganisms on the growing medium respiration and root weight of sweet pepper transplants after 5 weeks of growth.

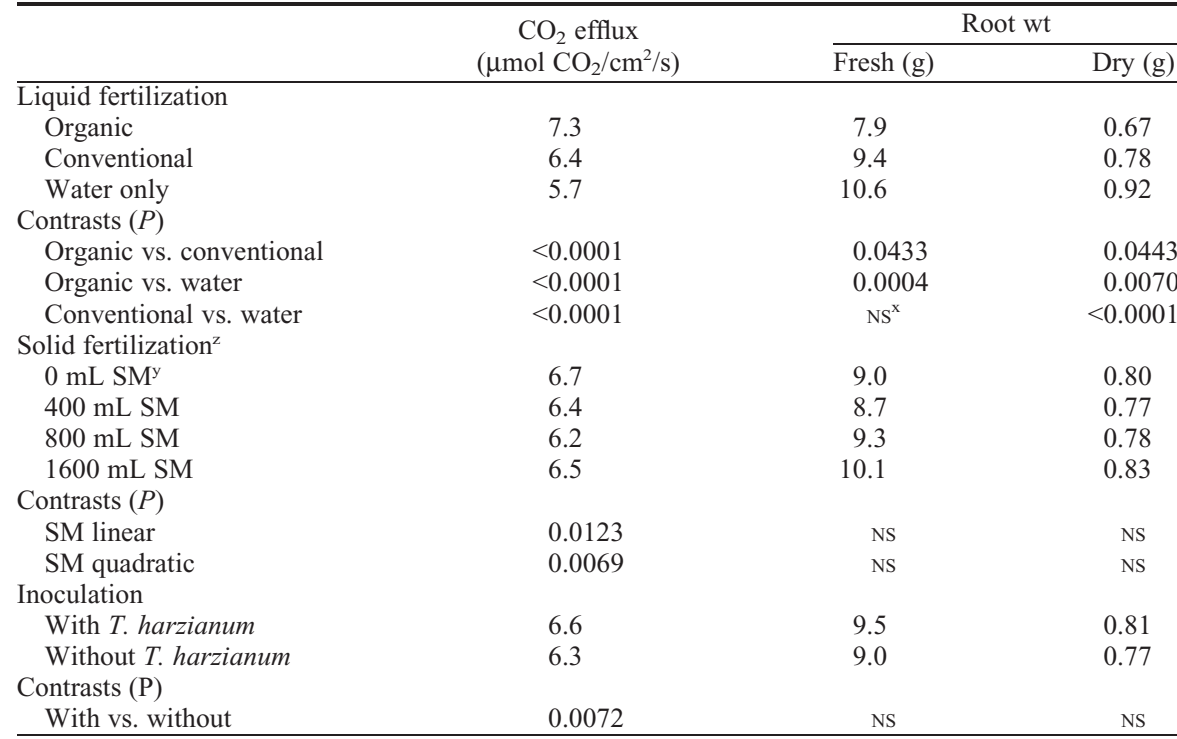

Data were analyzed using contrasts with a level of significance of $P \leq 0.05$.

${ }^{\mathrm{z}}$ Amount mixed in $1 \mathrm{~m}^{3}$ of growing medium.

${ }^{\mathrm{y}} \mathrm{SM}=$ shrimp meal.

$\mathrm{x}_{\mathrm{NS}}=$ nonsignificant

Data are means of $\mathrm{n}=5$. Contrast for SM cubic was not significant at $P<0.05$ for all measured parameters

Table 6. Carbohydrates partitioning between plant organs in sweet pepper transplants after 5 weeks of growth with water only or an organic or a conventional liquid fertilization.

\begin{tabular}{|c|c|c|c|c|}
\hline & \multicolumn{2}{|c|}{ Fresh wt } & \multicolumn{2}{|c|}{ Dry wt } \\
\hline & Percent shoot & Percent roots & Percent shoot & Percent roots \\
\hline \multicolumn{5}{|l|}{ Liquid fertilization } \\
\hline Organic & 85.6 & 14.4 & 87.9 & 12.1 \\
\hline Conventional & 84.2 & 15.8 & 87.2 & 12.8 \\
\hline Water only & 76.8 & 23.2 & 82.4 & 17.6 \\
\hline \multicolumn{5}{|l|}{ Contrasts $(P)$} \\
\hline Organic vs. conventional & $\mathrm{NS}^{\mathrm{z}}$ & NS & NS & NS \\
\hline Organic vs. water & $<0.0001$ & $<0.0001$ & $<0.0001$ & $<0.0001$ \\
\hline Conventional vs. water & $<0.0001$ & $<0.0001$ & $<0.0001$ & $<0.0001$ \\
\hline
\end{tabular}

Data were analyzed using contrasts with a level of significance of $P \leq 0.05$.

${ }^{\mathrm{z}} \mathrm{NS}=$ nonsignificant

Data are means of $\mathrm{n}=5$.

$\mathrm{CO}_{2}$ efflux from the growing medium. Significant contrasts $(P<0.05)$ are presented in Table 7. The interaction among liquid fertilization, solid fertilization (shrimp and kelp meal), and inoculation with $T$. harzianum was not significant. The $\mathrm{CO}_{2}$ emission from the growing medium 5 weeks after transplanting was significantly higher when plants were fertilized using the organic nutrient solution compared with the other two treatments (Table 5). Addition of shrimp meal had little effect on actual values of $\mathrm{CO}_{2}$ emission although a linear and quadratic effect was observed (Table 5). Inoculation with $T$. harzanium enhanced $\mathrm{CO}_{2}$ emission from the growing medium, although this increase represents only $5 \%$ of the $\mathrm{CO}_{2}$ efflux (Table 5).

Fluorescein diacetate hydrolysis. Significant contrasts $(P<0.05)$ are presented in Table 7. Inoculation of the growing medium with $T$. harzianum did not affect FDA hydrolysis. Inclusion of shrimp meal in the growing medium affected FDA hydrolysis in a significant linear manner (Table 8). At 5 weeks of growth, microbial activity increased as amount containing $1600 \mathrm{~mL} \cdot \mathrm{m}^{-3}$ of shrimp meal and also higher when the medium contained 50 $\mathrm{mL} \cdot \mathrm{m}^{-3}$ of kelp meal compared with the other media. The lowest $\mathrm{pH}$ was in the medium containing no shrimp meal and no kelp meal. At 10 weeks after transplanting, a lower $\mathrm{pH}$ was observed in the medium that received liquid organic fertilization compared with liquid conventional fertilization or water only (Table 9). Before transplanting, EC values were highest in the medium with the higher amount of shrimp meal (linear effect), whereas no significant difference in EC occurred by 10 weeks (Table 9). At 10 weeks after transplanting, EC values were higher in the medium receiving organic compared with conventional fertilization or water only (Table 9). No significant difference occurred for the $T$. harzianum inoculation before transplanting or at the 10 -week evaluation.

\section{Discussion}

Production of high-quality organic sweet pepper transplants is the first step in achieving optimum fruit production in year-around greenhouse production. However, organic regulations often restrict use of liquid fertilizers for certified organic transplants production because the main source of nutrients must be provided by the growing medium. This increases the challenge of producing healthy sweet pepper transplants with a balance between the shoot and the root within a small volume of growing medium, which contains a source of nutrient that is enough to last until final transplanting.

This study focused on a few available and commonly used organic fertilizers and an OMRI listed liquid fertilizer. Other studies tested a wider range of organic fertilizers, although not all certifiable under Canadian regulation, with variable results. Gagnon and Berrouard (1994) showed the good potential of blood, feather, and crab shell meals as organic fertilizers as well as the adverse effect of canola and alfalfa meals on tomato (Solanum lycopersicum L.) transplant growth. A similar phytotoxic effect of plant-based fertilizers was also reported by Koller et al. (2004) on organic vegetable transplants. Compost and vermicompost, although often considered a limited source of nutrients in the short term, has produced good results for vegetable transplant production (Arancon et al., 2004; OzoresHampton et al., 1999; Raviv et al., 1998; Reis et al., 1998). However, not all composts are the same, and not all show potential as good potting media for transplant production, mainly as a result of the low mineralization rate, $\mathrm{N}$ immobilization, and high salinity (Clark and Cavigelli, 2005). Raviv et al. (2005) report that $\mathrm{N}$ availability is often the main aspect affecting organic plant growth in containers. Other plant-based fertilizers (potato protein, malt sprouts, and vinasse) and animal-based fertilizers (feather and horn powder) also exhibited good potential for transplant production (Koller et al., 2004). One difference between organic and quickly released conventional fertilizers is availability of nutrients, 
Table 7. $P$ values for contrasts used to evaluate $\mathrm{CO}_{2}, \mathrm{pH}$, electrical conductivity (EC), and fluorescein diacetate (FDA) hydrolysis of growing medium used to grow sweet pepper plants.

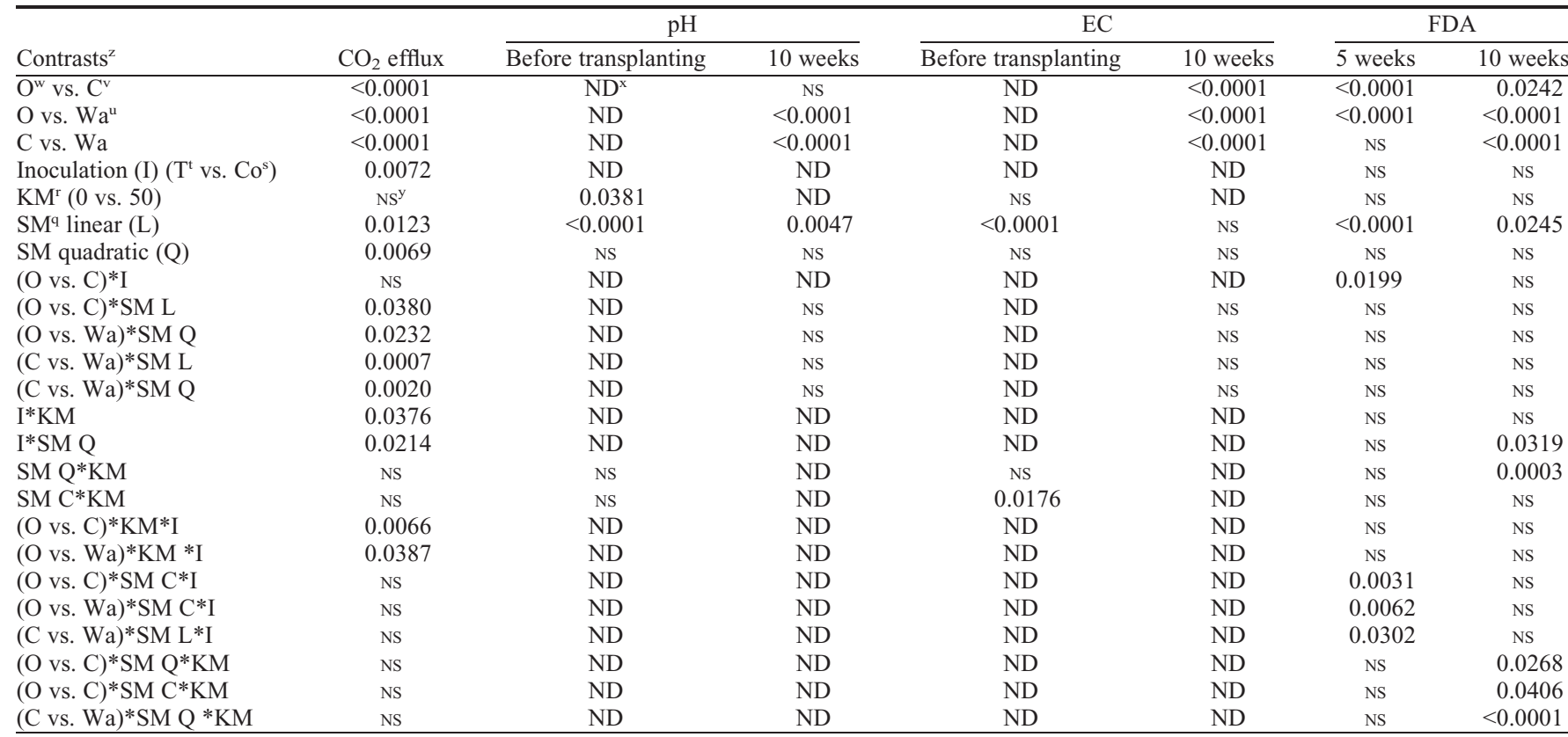

${ }^{\mathrm{z}}$ Only contrasts with a significant $P$ value for at least one of the parameter tested are shown.

$\mathrm{y}_{\mathrm{NS}}=$ nonsignificant.

${ }^{\mathrm{x}} \mathrm{ND}=$ not determined.

${ }^{\mathrm{w}} \mathrm{O}=$ organic liquid fertilization.

${ }^{\mathrm{v}} \mathrm{C}=$ conventional liquid fertilization.

${ }^{\mathrm{u}} \mathrm{Wa}=$ water only.

${ }^{\mathrm{t}} \mathrm{T}=$ Trichoderma harzianum

${ }^{\mathrm{s}} \mathrm{Co}=$ control.

${ }^{\mathrm{r}} \mathrm{KM}=$ kelp meal.

${ }^{\mathrm{q}} \mathrm{SM}=$ shrimp meal.

Table 8. Fluorescein diacetate hydrolysis evaluation from the growing medium of sweet pepper transplants grown for 5 and 10 weeks under organic and conventional fertilization.

\begin{tabular}{lcc}
\hline & Fluorescein diacetate hydrolysis $(\mu \mathrm{g}$ fluorescein $/ \mathrm{g} / \mathrm{h})$ \\
\cline { 2 - 3 } & 5 weeks & 10 weeks \\
\hline Solid fertilization & 2.53 & \\
$0 \mathrm{~mL} \mathrm{SM}$ & 3.15 & 7.41 \\
$400 \mathrm{~mL} \mathrm{SM}$ & 3.12 & 8.08 \\
$800 \mathrm{~mL} \mathrm{SM}$ & 4.21 & 10.01 \\
$1600 \mathrm{~mL} \mathrm{SM}$ & & 8.93 \\
Contrasts $(P)$ & $<0.0001$ & \\
$\quad$ SM linear & 2.11 & 0.0245 \\
Liquid fertilization & 4.00 & 11.72 \\
Organic & 3.61 & 10.01 \\
Conventional & & 4.18 \\
$\quad$ Water only & $<0.0001$ & 0.0242 \\
Contrasts $(P)$ & $<0.0001$ & $<0.0001$ \\
$\quad$ Organic vs. conventional & $\mathrm{NS}^{\mathrm{y}}$ & $<0.0001$ \\
$\quad$ Organic vs. water & & \\
Conventional vs. water &
\end{tabular}

Data were analyzed using contrasts with a level of significance of $P \leq 0.05$.

${ }^{\mathrm{z}} \mathrm{SM}=$ shrimp meal (amount mixed in $1 \mathrm{~m}^{3}$ of growing medium).

${ }^{\mathrm{y}_{\mathrm{NS}}}=$ nonsignificant.

Data are means of $\mathrm{n}=5$. Contrast for SM quadratic and cubic were not significant at $P<0.05$ at 5 and 10 weeks.

which is even more problematic in the case of production of young vegetable transplants that have a relatively sensitive root system and that are produced in a small volume of growing medium. Organic fertilization is often unbalanced and because it is often based on mineralization, transplant needs and availability of nutrients often shift in time. The amount of fertilizer that should be added to the medium has to be low enough so the salinity does not cause damage to the developing root system but high enough to sustain plant growth up to transplanting. EC was much higher in the growing medium that received the organic fertilizer compared with that receiving the conventional fertilizer. However, although EC increased in the case of organic fertilization, values stayed within a range acceptable for sweet pepper transplant production. Organic fertilizers usually tend to increase $\mathrm{pH}$, but the opposite was observed in this study with the liquid organic fertilizer, in which $\mathrm{pH}$ seemed to be lower. In contrast, $\mathrm{pH}$ increased slightly over time for the conventional and the water-only treatment.

Quality organically grown sweet pepper transplants can be obtained, although there was a delay in growth using a solid initial fertilization without using liquid organic fertilizers over a short period of time (in this case 5 weeks). After 5 weeks, sweet pepper transplants need to be planted in soil or provided with additional fertilizer to avoid major nutrient deficiencies, as observed with transplants that received water only. Sweet pepper transplants were smaller after 5 weeks indicating that the source of nutrients was being reduced. Carbohydrate partitioning in those transplants indicated that a higher percentage of biomass was allocated to roots, most likely to increase their potential to absorb available nutrients. A stronger root system could be beneficial to establishment of transplants once they are planted in the final growing medium or soil.

Jack et al. (2011) reported that amendments causing a delay in early seedling growth can result in higher biomass accumulation once seedlings are transplanted. They demonstrated that growing medium and rhizosphere bacterial communities were affected by different organic amendments applied to seedlings, which could explain, at least in part, the difference in plant growth after transplanting (Jack et al., 2011). Organic fertilizers such as compost can be viewed as a good source of microorganisms, whereas others, which serve 
Table 9. Values of $\mathrm{pH}$ and electrical conductivity (EC) of growing medium of sweet pepper transplants before planting or after transplants were grown for 10 weeks under organic and conventional fertilization.

\begin{tabular}{|c|c|c|c|c|}
\hline & \multicolumn{2}{|c|}{ Before planting } & \multicolumn{2}{|c|}{10 weeks } \\
\hline & $\mathrm{pH}$ & $\mathrm{EC}\left(\mathrm{mS} \cdot \mathrm{cm}^{-1}\right)$ & $\mathrm{pH}$ & $\overline{\mathrm{EC}}\left(\mathrm{mS} \cdot \mathrm{cm}^{-1}\right)$ \\
\hline \multicolumn{5}{|l|}{ Solid fertilization } \\
\hline $0 \mathrm{~mL} \mathrm{SM}^{\mathrm{z}}$ & 5.60 & 0.38 & 5.90 & 1.09 \\
\hline $400 \mathrm{~mL} \mathrm{SM}$ & 5.67 & 0.42 & 5.94 & 1.00 \\
\hline $800 \mathrm{~mL} \mathrm{SM}$ & 5.70 & 0.49 & 6.03 & 1.02 \\
\hline $1600 \mathrm{~mL} \mathrm{SM}$ & 5.85 & 0.55 & 6.12 & 1.09 \\
\hline \multicolumn{5}{|l|}{ Contrasts $(P)$} \\
\hline SM linear & $<0.0001$ & $<0.0001$ & 0.0047 & NS \\
\hline \multicolumn{5}{|l|}{ Kelp meal } \\
\hline $0 \mathrm{~mL} \mathrm{KM}^{\mathrm{y}}$ & 5.68 & 0.46 & $\mathrm{ND}^{\mathrm{w}}$ & ND \\
\hline $50 \mathrm{~mL} \mathrm{KM}$ & 5.72 & 0.47 & ND & ND \\
\hline \multicolumn{5}{|l|}{ Contrasts $(P)$} \\
\hline Without vs. 50 & 0.0381 & $\mathrm{NS}^{\mathrm{x}}$ & ND & ND \\
\hline \multicolumn{5}{|l|}{ Liquid fertilization } \\
\hline Organic & ND & ND & 4.74 & 2.24 \\
\hline Conventional & ND & ND & 6.65 & 0.64 \\
\hline Water only & ND & ND & 6.59 & 0.28 \\
\hline \multicolumn{5}{|l|}{ Contrasts } \\
\hline Organic vs. conventional & ND & ND & $<0.0001$ & $<0.0001$ \\
\hline Organic vs. water & ND & ND & $<0.0001$ & $<0.0001$ \\
\hline Conventional vs. water & ND & ND & NS & $<0.0001$ \\
\hline
\end{tabular}

Data were analyzed using contrasts with a level of significance of $P \leq 0.05$.

${ }^{2} \mathrm{SM}=$ shrimp meal (amount mixed in $1 \mathrm{~m}^{3}$ of growing medium).

${ }^{\mathrm{y}} \mathrm{KM}=$ kelp meal (amount mixed in $1 \mathrm{~m}^{3}$ of growing medium).

${ }^{\mathrm{x}_{\mathrm{NS}}}=$ nonsignificant.

${ }^{\mathrm{w}} \mathrm{ND}=$ not determined.

Data are means of $\mathrm{n}=5$. Contrast for SM quadratic and cubic were not significant at $P<0.05$ for $\mathrm{pH}$ and EC measured before transplanting and at 10 weeks.

more as a source of food for microorganisms, can help stimulate microbial communities (Raviv et al., 2005). Growing medium respiration, measured in this case as $\mathrm{CO}_{2}$ efflux from the medium, is a good indicator of biological soil activity (microbial activity and root respiration). In this experiment, transplants that received liquid organic fertilization exhibited higher media respiration, which could be related to a stimulation of the biological and, more precisely, of the microbial activity every time transplants were fertilized. Increased respiration in organic treatments was not associated with respiration from the root system. Root weight of organically produced transplants was equal to $74.6 \%$ that of the wateronly treatment but respiration in the water treatment was equal to $78.9 \%$ that of the organic treatment. Over time, general microbial activity increased as a result of treatment with liquid fertilizer as indicated by the higher hydrolysis of FDA. Solid fertilization seemed to minimally affect growing medium respiration rate, but it affected the general microbial activity as demonstrated by FDA hydrolysis. Organic transplant production could benefit from activation of the microbial activity in the growing medium. Instead of relying on organic liquid fertilizers to do so, use of compost tea or manure extract could be a good option, but only as a source of microorganisms. Those have been shown to increase the $\mathrm{CO}_{2}$ efflux, and the biological activity, in container-grown geraniums (Pelargonium zonale L'Hér.) (Gravel et al., 2009). Koné et al. (2010) reported that microbial activity of compost tea is most likely the result of its antagonistic activity against pathogens. Microbial communities were not evaluated during the course of this experiment.
However, because no symptoms of any diseases were observed in any treatments, neither on shoot or roots, this increase is most likely linked to a stimulation of the general microbial activity, including beneficial microorganisms. Increasing microbial activity in the rhizosphere influences plant growth even when plants have been transplanted (Jack et al., 2011). Russo (2006) concluded that inoculated bacteria can affect a plant rhizosphere by rendering the environment conducive to plant development. This could have an effect on future sweet pepper plant yields. Although the increase was relatively small, inoculation with $T$. harzianum increased medium respiration as well as the general microbial activity. Effect of inoculants on respiration rate could be related to the association of the fungus and the plant. Nevertheless, a low fertilizer input cropping system, which is characteristic of organic farming, could benefit the most from an association between plants and beneficial microorganisms. Efficiency of organic fertilizers increases when used in combination with beneficial microorganisms such as arbuscular mycorrhizal fungi (Perner et al., 2007). Raviv et al. (1998) showed that coinoculation of organic cabbage (Brassica oleracea L.) seedlings with both mycorrhiza and Trichoderma sp. improved growth. Although no difference in transplant growth was observed between non-inoculated plants and those inoculated with $T$. harzianum during the course of this experiment, a beneficial effect might have been observed later in the production cycle like in other studies (Jack et al., 2011; KokalisBurelle et al., 2006). Kokalis-Burelle et al. (2002) showed that vigor and survival of pepper plants were improved post-transplanting in soil by inoculating roots of transplants with plant growth-promoting rhizobacteria. Not only do beneficial microorganisms improve healthy plant growth, but they can also protect plants against soilborne pathogens when applied at an early stage of development (Avis et al., 2008; Kloepper et al., 2004). Furthermore, inoculation of transplant rhizosphere before transplanting is more cost-effective and much more practical than at a larger scale such as an in-ground organic production system.

Benefits, other than from a nutrient standpoint, can be achieved using organic fertilizers in production of vegetable transplants. To obtain high-quality organic sweet pepper transplants, a combination of inoculation with T. harzianum, use of solid organic fertilization $\left(1600 \mathrm{~mL} \cdot \mathrm{m}^{-3}\right.$ of shrimp meal with $50 \mathrm{~mL} \cdot \mathrm{m}^{-3}$ of kelp meal), and of organic liquid fertilization, but only as a complementary source of nutrients, should be used. Reducing use of organic liquid fertilization to a minimum would result in a stronger root system, as observed with the water-only plants, while still being able to obtain adequate shoot development and to benefit from an increase in the microbial activity.

\section{Literature Cited}

Arancon, N.Q., C.A. Edwards, R. Atiyeh, and J.D. Metzger. 2004. Effects of vermicomposts produced from food waste on the growth and yields of greenhouse peppers. Bioresour. Technol. 93: 139-144.

Avis, T.J., V. Gravel, H. Antoun, and R.J. Tweddell. 2008. Multifaceted beneficial effects of rhizosphere microorganisms on plant health and productivity. Soil Biol. Biochem. 40:1733-1740.

Clark, S. and M. Cavigelli. 2005. Suitability of composts as potting media for production of organic vegetable transplants. Compost Sci. Util. 13:150-156.

Dorais, M. 2007. Organic production of vegetables: State of the art and challenges. Can. J. Plant Sci. 87:1055-1066.

Gagnon, B. and S. Berrouard. 1994. Effects of several organic fertilizers on growth of greenhouse tomato transplants. Can. J. Plant Sci. 74: $167-168$

Gravel, V., M. Dorais, C. Ménard, and S. Pepin. 2011. Soil salinization of organically-grown greenhouse tomato. Proc. of the Third Scientific Conference of the International Society of Organic Agriculture Research (ISOFAR), 17th IFOAM Organic World Congress, Seoul, South Korea, 27 Sept. to 1 Oct. 2011, Organic is Life: Knowledge for tomorrow. Volume 1 Organic Crop production. p. 436-440.

Gravel, V., C. Ménard, and M. Dorais. 2009. Pythium root rot growth responses of organically grown geranium plants to beneficial microorganisms. HortScience 44:1622-1627.

Jack, A.L.H., A. Rangarajan, S.W. Culman, T. Sooksa-Nguan, and J.E. Thies. 2011. Choice of organic amendments in tomato transplants has lasting effects on bacterial rhizosphere communities and crop performance in the field. Appl. Soil Ecol. 48:94-101.

Kloepper, J.W., M.S. Reddy, R. RodríguezKabana, D.S. Kenney, N. Kokalis-Burelle, N. Martinez-Ochoa, and C.S. Vavrina. 2004. Application for rhizobacteria in transplant production and yield enhancement. Acta Hort. 631:217-229.

Kokalis-Burelle, N., J.W. Kloepper, and M.S. Reddy. 2006. Plant growth-promoting rhizobacteria as 
transplant amendments and their effects on indigenous rhizosphere microorganisms. Appl. Soil Ecol. 31:91-100.

Kokalis-Burelle, N., C.S. Vavrina, E.N. Rosskopf, and R.A. Shelby. 2002. Field evaluation of plant growth-promoting rhizobacteria amended transplant mixes and soil solarization for tomato and pepper production in Florida. Plant Soil 238:257-266.

Koller, M., T. Alföldi, M. Siegrist, and F. Weibel. 2004. A comparison of plant and animal based fertiliser for the production of organic vegetable transplants. Acta Hort. 631:209-215.

Koné, S.B., A. Dionne, R.J. Tweddell, H. Antoun, and T.J. Avis. 2010. Suppressive effect of nonaerated compost teas on foliar fungal pathogens of tomato. Biol. Control 52:167-173.

Ozores-Hampton, M., C.S. Vavrina, and T.A. Obreza. 1999. Yard trimming-biosolids compost: Possible alternative to Sphagnum peat moss in tomato transplant production. Compost Sci. Util. $7: 42-49$.
Perner, H., D. Schwarz, C. Bruns, P. McTder, and E. George. 2007. Effect of arbuscular mycorrhizal colonization and two levels of compost supply on nutrient uptake and flowering of pelargonium plants. Mycorrhiza 17:469-474.

Raviv, M., Y. Oka, J. Katan, Y. Hadar, A. Yogev, S. Medina, A. Krasnovsky, and H. Ziadna. 2005. High-nitrogen compost as a medium for organic container-grown crops. Bioresour. Technol. 96: 419-427.

Raviv, M., B.Z. Zaidman, and Y. Kapulnik. 1998. The use of compost as a peat substitute for organic vegetable transplants production. Compost Sci. Util. 6:46-52.

Reis, M., F.X. Martinez, M. Soliva, and A.A. Monteiro. 1998. Composted organic residues as a substrate component for tomato transplant production. Acta Hort. 469:263-273.

Russo, V.M. 2005. Organic vegetable transplant production. HortScience 40:623-628.

Russo, V.M. 2006. Biological amendment, fertilizer rate, and irrigation frequency for organic bell pepper transplant production. HortScience 41:1402-1407.

Schnurer, J. and T. Rosswall. 1982. Fluorescein diacetate hydrolysis as a measure of total microbial activity in soil and litter. Appl. Environ. Microbiol. 43:1256-1261.

Tremblay, N. and A. Gosselin. 1998. Effect of carbon dioxide enrichment and light. HortTechnology 8:524-528.

Tremblay, N. and M. Sénécal. 1988. Nitrogen and potassium in nutrient solution influence seedling growth of four vegetable species. HortScience 23:1018-1020.

Voogt, W., W.J.M. Cuijpers, P.H.E. de Visser, G.J.H.M. van de Burgt, and A. van Winkel. 2011. Nutrient management in organic greenhouse production; navigation between constraint. Acta Hort. 915:75-82.

Wubs, A.M., E. Heuvelink, L. Hemerik, and L.F.M. Marcelis. 2011. Stochastic dynamic simulation of fruit abortion: A case study of sweet pepper. Acta Hort. 893:765-772. 